\title{
Physics Instruction That Facilitates Learning Among Underrepresented Groups
}

\author{
Jennifer Keil, Nicole Schrode, and Rebecca Stober \\ School of Education, University of Colorado, 249 UCS, Boulder, Colorado, 80309
}

\begin{abstract}
The Physics and Everyday Thinking High School (PET-HS) curriculum, engages students in science practices of generating and defending claims using evidence and argumentation as a means of developing and formalizing physics principles. This preliminary study focuses on how students who are typically underrepresented or under performing in traditional physics classes respond to the learning cycle used in the PET-HS curriculum. Students in PET-HS classes in two different schools were given the same assessments before and after developing ideas about three commonly misunderstood concepts. Findings suggest that students from underrepresented groups show no significant difference in posttest score outcomes as compared to students in majority groups. We will discuss how non-traditional curricula, like PET-HS, may facilitate a learning environment where all students are given access to scientific principles and practices.

Keywords: Inquiry Learning, Student Discourse, Argumentation
\end{abstract}

\section{INTRODUCTION}

The National Assessment of Educational Progress (NAEP) shows consistently that students who identify as American Indian or Alaska Native, Black, Hispanic or Latino, Native Hawaiian or other Pacific Islander score far below those who identify as White [1]. Similarly, students with learning disabilities and English Language Learners (ELLs) scored lower than peers [2]. Differences between female and male performance in physics have also been documented. Female students tend to score lower on Advanced Placement, and other tests as compared to their male peers [3]. Bianchini (2012) suggests that these outcomes may result from internalization of stereotypes about their under preparedness rather than true ability [4]. Poverty levels and other sociocultural factors also play a role in what amounts to underrepresentation of students from specific groups in STEM college classes, majors, and fields.

The Physics in Everyday Thinking High School curriculum (PET-HS), used by the teachers in this study, utilizes structures that are designed to empower students through access to both the science content and scientific practices. The PET-HS curriculum is closely aligned with the Next Generation Science Standards (NGSS). The NGSS serves as a guideline for incorporating scientific practices, which overlap with learning strategies that may lead to better outcomes for underrepresented groups [5]. The PET-HS curriculum uses strategies such as using students' everyday discourse, descriptions, and fostering connection to their social worlds'. This seem to increase success in minority populations [4]. Belleau (2013) found that female, non-native English speakers excelled when learning physics in a class that emphasized scientific practices such as encouraging student dialogue, collecting and interpreting evidence, and building and applying models, as per the NGSS science practices [6].

The PET-HS curriculum aims to put students in the position to articulate and defend their own ideas using evidence derived with their peers. As a result, we have observed that the majority of students seem motivated to engage with concepts to create scientifically accurate arguments. In this study, we sought to investigate whether utilizing the PET-HS curriculum leads to better outcomes for underrepresented students within a physics class. We explored the question, "How do learning gains compare across underrepresented subgroups when using an inductive-based curriculum, like the PET-HS curriculum?"

\section{RESEARCH CONTEXT}

This study reports preliminary results from data from PET-HS classes in two public high schools. The classes were taught by two different PET-HS teachers who have completed professional development and taught the curriculum for two or more years. One school site is a small, urban public high school where $64 \%$ of students qualify for free or reduced lunch programs. The ethnic diversity of this school is $68 \%$ Hispanic, $25 \%$ White, $2 \%$ Black, $1 \%$ American Indian, and 1\% Asian. Additionally, $23 \%$ of students within this school classify as ELL. The second site is a large suburban public high school with $37 \%$ of students qualifying for free or reduced lunch programs. The ethnic diversity of this school is 33\% Hispanic, 62\% White, $1 \%$ Black, $1 \%$ American Indian, and 2\% Asian. Additionally, $20 \%$ of students within this school classify as ELL. Students in both sets of classes contained high concentrations of the schools' low socio-economic, minority, and ELL populations.

Students in both school settings were taught using the PET-HS learning cycle. The physics activities and classroom structures were designed for students to lead their own learning with support from the instructor. Each learning cycle began with students identifying their initial ideas. Afterwards, they performed experiments and analyzed their results. Finally, each group shared and modified their thinking in a whole class discussion. Throughout this process the instructor's role was to help 
students clarify their ideas through questioning and consensus building, rather than confirming answers.

\section{METHODOLOGY}

\section{A. Data Collection}

Three physics concepts that are commonly misunderstood within high school physics classrooms were chosen for study across both PET-HS classes: positive and negative velocity components, Newton's Second Law, and gravitational acceleration. Before the learning cycle began, students were given a pretest, as shown in Fig.1, to assess their prior knowledge of these topics. Students then went through the learning cycle; after which they were given the same assessment as a posttest. We used these assessment questions, which were vetted by other high school teachers, in efforts of examining students' learning of these specific concepts. We did not use larger assessments such as the FCI or FMCE because we wanted to target specific concepts at the end of instruction on each topic. While we were not looking specifically for student difficulties with the concepts, the method of using a specific small set of questions pre and post is similar to the design-research methodology used by McDermott and the University of Washington Physics Education Research Group [7]. Students were also given a questionnaire asking them to identify their gender, language spoken at home, and ethnicity. Any student who identified a language other than English as the language primarily spoken at home was classified as an English Language Learner.

\section{B. Data Analysis}

Pre and posttests were scored using a common rubric, which was established by a group of teachers and tested for reliability. Responses were analyzed based on subgroups designated as underrepresented including students with Individualized Education Plans (IEPs) or 504 plans. IEPs are written documents outlining specialized instruction for students with disabilities according to assessed needs, while 504 plans require accommodations for students with disabilities in general education courses. We compared performance outcomes and learning gains of various subgroups (i.e. female vs. male, IEP vs. non IEP, ELL vs. non-ELL, and minority students vs. white students). Pre and posttest scores were used to calculate average outcomes and normalized learning gains for each subgroup. The average posttest scores were compared for statistically significance using t-tests.

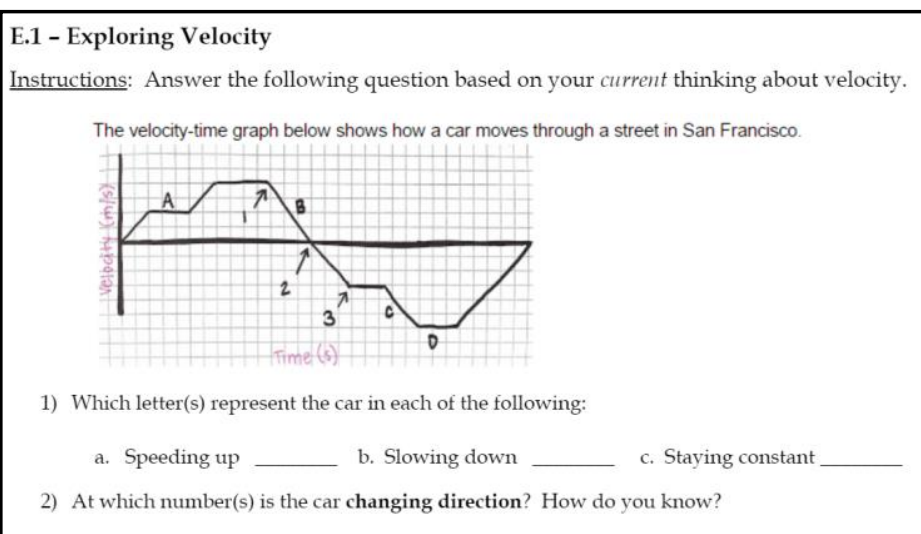

F.2 - Mass \& Acceleration

Instructions: Examine the speed-time graph below.

Two different objects are pushed with the exact same force.

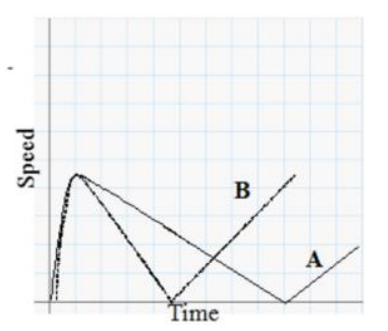

1. Based on the graph, which object (A or B) would you expect to have a greater mass?

2. Explain your answer to the question above.

G.1 - Gravitational Force \& Acceleration

Instructions: Examine the diagram below of a person holding a soccer ball and a bowling ball, then answer the question that follows.

- The soccer ball has a mass of $0.4 \mathrm{~kg}$.

- The bowling ball has a mass of $4 \mathrm{~kg}$.

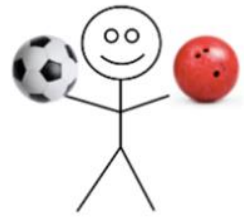

1) Which object will hit the ground first if both were dropped at the same time? |

2) Explain why you think so

FIG 1. Pre \& post assessments.

\section{FINDINGS}

\section{Male and female students demonstrated no significant difference in performance outcomes.}

For the three concepts assessed, female students demonstrated nearly equivalent average posttest scores as compared to male students, as shown in Fig. 2. All three concepts assessed showed no significant difference in performance ( $\mathrm{p}$ values of $0.65,0.64$, and 0.18 , respectively). 


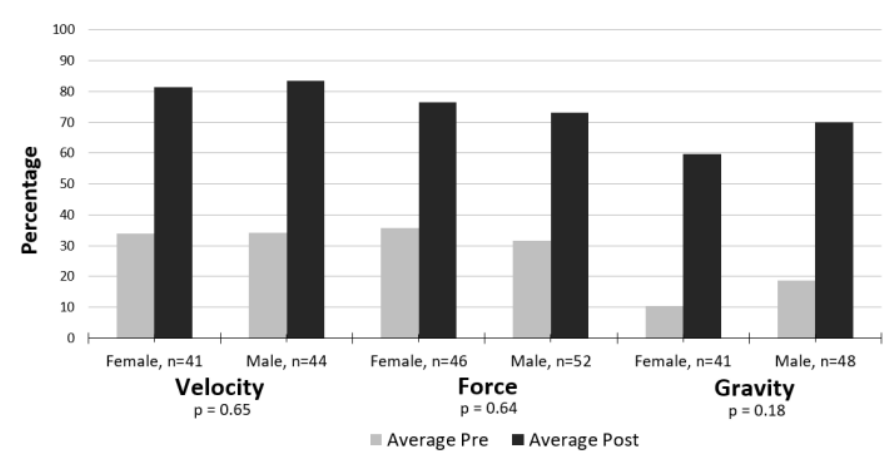

FIG 2. Male and female student gains.

Additionally, Tables 1, 2, \& 3 show that male and female students demonstrated nearly equivalent normalized learning gains (NLG) on all three concepts assessed.

TABLE I. Velocity performance data.

\begin{tabular}{lllll}
\hline Subgroup & $\begin{array}{l}\text { Sample } \\
\text { Size }\end{array}$ & $\begin{array}{l}\text { Average } \\
\text { Pretest } \\
\text { Score }\end{array}$ & $\begin{array}{l}\text { Average } \\
\text { Posttest } \\
\text { Score }\end{array}$ & NLG \\
\hline Female & $\mathrm{n}=41$ & $33.9 \%$ & $81.3 \%$ & 0.7 \\
Male & $\mathrm{n}=44$ & $34.1 \%$ & $83.5 \%$ & 0.7 \\
IEP & $\mathrm{n}=9$ & $22.2 \%$ & $87 \%$ & 0.8 \\
Non-IEP & $\mathrm{n}=76$ & $35.4 \%$ & $81.9 \%$ & 0.7 \\
ELL & $\mathrm{n}=32$ & $31.3 \%$ & $77.3 \%$ & 0.6 \\
Non-ELL & $\mathrm{n}=53$ & $35.7 \%$ & $85.6 \%$ & 0.7 \\
Minority & $\mathrm{n}=49$ & $33.3 \%$ & $81.8 \%$ & 0.7 \\
Non-minority & $\mathrm{n}=29$ & $37.4 \%$ & $87.4 \%$ & 0.8 \\
\hline
\end{tabular}

TABLE 2. Second Law performance data.

\begin{tabular}{lllll}
\hline Subgroup & $\begin{array}{l}\text { Sample } \\
\text { Size }\end{array}$ & $\begin{array}{l}\text { Average } \\
\text { Pretest } \\
\text { Score }\end{array}$ & $\begin{array}{l}\text { Average } \\
\text { Posttest } \\
\text { Score }\end{array}$ & NLG \\
\hline Female & $\mathrm{n}=46$ & $35.7 \%$ & $76.6 \%$ & 0.6 \\
Male & $\mathrm{n}=52$ & $31.7 \%$ & $73 \%$ & 0.6 \\
IEP & $\mathrm{n}=11$ & $25 \%$ & $65.9 \%$ & 0.5 \\
Non-IEP & $\mathrm{n}=86$ & $34.8 \%$ & $75.9 \%$ & 0.6 \\
ELL & $\mathrm{n}=37$ & $33.1 \%$ & $80.4 \%$ & 0.7 \\
Non-ELL & $\mathrm{n}=60$ & $34 \%$ & $71.3 \%$ & 0.5 \\
Minority & $\mathrm{n}=64$ & $33.7 \%$ & $75.4 \%$ & 0.6 \\
Non-minority & $\mathrm{n}=31$ & $32.6 \%$ & $73.5 \%$ & 0.5 \\
\hline
\end{tabular}

2. Students with learning disabilities showed no significant difference in performance compared to other students.

Again, on all three assessments, students with identified learning disabilities demonstrated no statistical difference between their average performance outcomes, as shown in Fig. 3. Additionally, students with IEPs or 504 plans
TABLE 3. Gravitational acceleration performance data.

\begin{tabular}{lllll}
\hline Subgroup & $\begin{array}{l}\text { Sample } \\
\text { Size }\end{array}$ & $\begin{array}{l}\text { Average } \\
\text { Pretest } \\
\text { Score }\end{array}$ & $\begin{array}{l}\text { Average } \\
\text { Posttest } \\
\text { Score }\end{array}$ & NLG \\
\hline Female & $\mathrm{n}=41$ & $10.5 \%$ & $59.8 \%$ & 0.5 \\
Male & $\mathrm{n}=48$ & $18.7 \%$ & $70.1 \%$ & 0.6 \\
IEP & $\mathrm{n}=12$ & $2.8 \%$ & $66.7 \%$ & 0.7 \\
Non-IEP & $\mathrm{n}=80$ & $16.7 \%$ & $65.2 \%$ & 0.6 \\
ELL & $\mathrm{n}=29$ & $14.9 \%$ & $65.4 \%$ & 0.6 \\
Non-ELL & $\mathrm{n}=63$ & $14.8 \%$ & $63.5 \%$ & 0.6 \\
Minority & $\mathrm{n}=54$ & $15.1 \%$ & $66.7 \%$ & 0.6 \\
Non-minority & $\mathrm{n}=38$ & $14.5 \%$ & $63.6 \%$ & 0.6 \\
\hline
\end{tabular}

showed nearly equal learning gains as their peers, as shown in Tables $1,2, \& 3$.

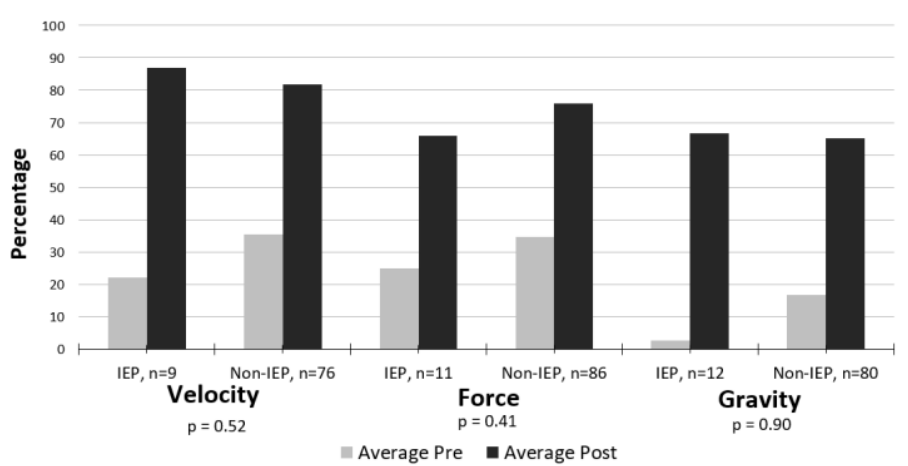

FIG 3. IEP and non-IEP student gains.

\section{Performance outcomes of ELLs were not statistically different from those of their peers.}

Students learning English demonstrated performance not statistically different from native English speakers, (see Fig. 4). Likewise, ELL students demonstrated equivalent learning gains with their peers, as shown in Tables 1,2 , and 3.

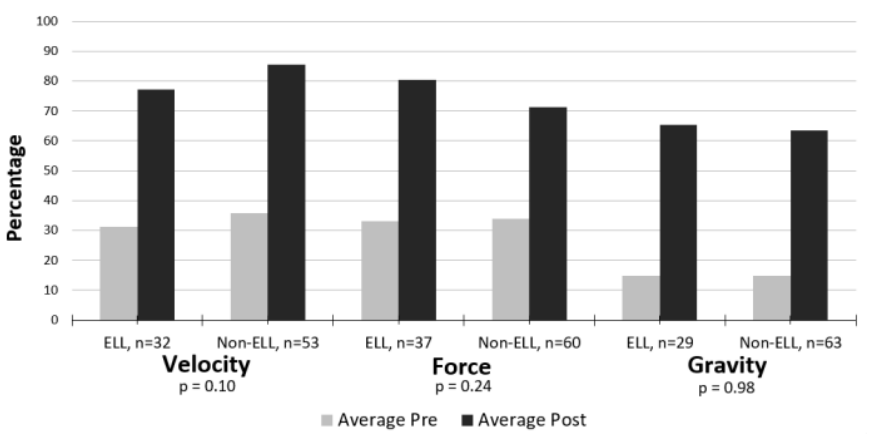

FIG 4. ELL and non-ELL student gains.

\section{Minority students demonstrated statistically equivalent performance as non-minority students.}

On all three physics assessments, minority students' performance showed no significant difference from that of 
their non-minority peers, as shown in Fig. 5. Furthermore, the average normalized learning gains between groups showed no difference, as shown in Tables 1, 2, and 3.

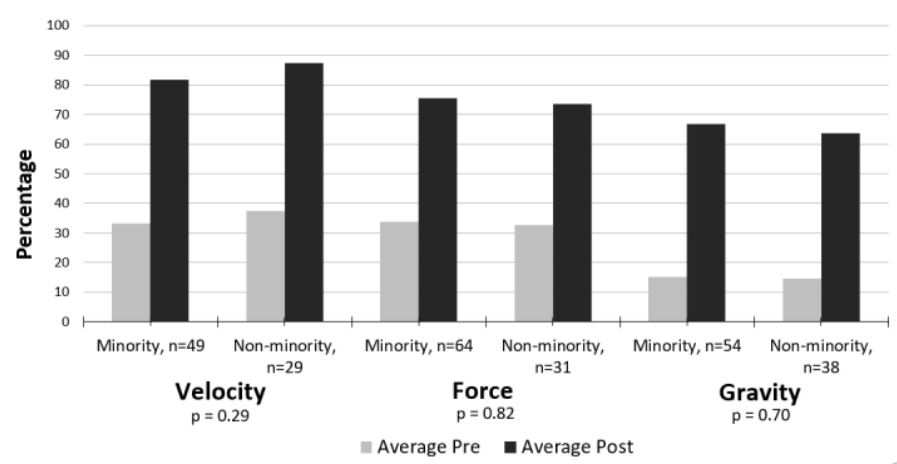

FIG 5. Minority and non-minority student performance.

\section{CONCLUSIONS}

Historically, particular student groups, such as female students, those with learning disabilities, non-native English speakers, and students belonging to minority groups, underperform when compared to their majority, male counterparts. Such underperformance may be a contributing factor to the low percentage of these student groups within post-secondary physics majors and careers. In this study, students from these underrepresented groups demonstrated comparable performance outcomes. This may indicate that inquiry-based, interactive curricula, like the PET-HS physics curriculum, may be provide a context for students to be successful in the physics classroom.

The findings of this study led researchers to evaluate the pedagogical factors that could account for the results. Within PET-HS and similar curricula, the role of the teacher differs from a traditional instructional format in the following ways: (1) teachers act more as facilitators of learning rather than experts sharing their knowledge with students. This is in alignment with NGSS Scientific and Engineering Practices. (2) Students engage directly with the collection and analysis of experimental data. Only after students have discovered underlying physics principles and reached consensus, are the formalized scientific principles and language presented to students.

Researchers hypothesize that these curricular aspects may set up a safe, supportive and comfortable setting for students to use both informal and academic language when learning about physics. This is in contrast to traditional high school physics instruction in which knowledge is acquired through teacher-led lectures and confirmatory lab experiences, which may account for the inaccessibility of the physics content for the subgroups of this study.

Another unique aspect of curricula like PET-HS is its collaborative nature. Throughout the learning cycle, all experimental data collection and analysis is performed within small groups in which students rely on each other to confirm findings and make sense of the collected data.
Students must practice communicating their results and engaging in evidence-based argumentation. Additionally, much of the PET-HS curriculum is centered around student-led discussion. This element of student-led discussion is unique compared to traditional instruction and may support student construction of knowledge and the development of epistemic agency.

More analysis, such as student interviews, is necessary to fully investigate and identify the critical components of learning environments that could lead to these results. Furthermore, an expansion of data collection in additional PET-HS classrooms and non-PET-HS classrooms is necessary to support the preliminary results presented in this paper.

It is important to note that the sample sizes present in this study act as a limiting factor on the results, particularly true in regards to IEP students; sample groups of such students ranged in size between nine and twelve. Additionally, the underrepresented subgroups identified in this study were based on national assessments which may differ from the conceptual assessment tools used in this study. For direct comparison, more research is needed in which non-PET-HS classrooms use the same data collection tools and assessments. Finally, it is important to note the teachers involved in the study have multi-year experience with the PET-HS curriculum; such experience and training may be necessary to achieve the preliminary results presented in this study.

\section{ACKNOWLEDGEMENTS}

The authors would like to thank the Streamline to Mastery program, supported by NSF Grant \# DUE 1340083, as well as Valerie Otero, Shelly Belleau, Emily Quinty, and Taylor Marino.

[1] U.S. Department of Education, Institute of Education Sciences, National Center for Education Statistics, (NAEP), 2009 and 2015 Science Assessments, (2015). https://www.nationsreportcard.gov/science 2015/\#gap s? grade $=12$.

[2] U.S. Department of Education, Institute of Education Sciences, National Center for Education Statistics (NAEP), 2009 and 2015 Science Assessments, (2015). https://www.nationsreportcard.gov/science 2015/\#groups?g $\underline{\text { rade }=12}$.

[3] M. Neuschatz, AIP Report, American Inst. of Physics, College Park, (1999), 13 - 15.

[4] J. Bianchini Sci. Education, 97, 163-166.

[5] O. Lee, E. Miller, and R. Januszyk, National Science Teachers Association, Arlington, (2015), 7 - 20, 61 - 118.

[6] S.N. Belleau and V.K. Otero, PERC Proceedings, (2013), 69-72.

[7] L. McDermott, American Journal of Physics 69, 1127 (2001); doi: 10.1119/1.1389280 